\title{
El Archivo General de la Nación en la era de la apertura de la información pública en México
}

\author{
Jorge Nacif Mina
}

En la era de la transparencia y el acceso a la información pública gubernamental, el liderazgo en la organización de los archivos de México del Archivo General de la Nación está sujeto a la tarea de asesoría y capacitación que proyecte en los archivos de la administración pública. Debe evitar convertirse en un auditor y sí en un asesor cuyo objetivo sea propiciar el derecho a la información y la rendición de cuentas, acciones que, a cuatro años de la publicación de los Lineamientos Generales en la materia, no se han cumplido en todas las dependencias y entidades de la Administración Pública Federal.

PALABRAS CLAVE: archivística, expedientes, información, derecho a la información, transparencia

\section{The Role of Mexico's General National Archive in an Age of Openness in Public Information}

In the age of transparency and access to governmental public information, the leadership of the General National Archive in organizing Mexico's archives is reflected through the advisory and training functions it performs for other public repository institutions. The General National Archive must avoid behaving as an auditor, and rather act as an advisor that seeks to promote the right to information and public accountability, which are practices that have not yet been adopted by all agencies and organisms of the federal government, even though it's been four years since the General Guidelines regarding those matters were published.

KEY WORDS: archivistics, dossiers, information, right to information, transparency

\footnotetext{
JORGE NACIF MINA: Instituto de Estudios Históricos Carlos de Sigüenza y Góngora, A.C. y Escuela Mexicana de Archivos, A.C., México-Distrito Federal jnacif.ieh@igo.com.mx
} 


\section{FUNDAMENTACIÓN}

A l querer realizar un análisis sobre el papel y el liderazgo del Archivo General de la Nación en la era de la transparencia y acceso a la información en México no podemos dejar de indagar en la problemática que los archivos de las dependencias y entidades de la Administración Pública Federal han tenido que enfrentar, no sólo para cumplir con una ley de transparencia y acceso a la información pública gubernamental, sino para establecer una organización interna que no se ha concretado en la realidad. Esta última es la responsabilidad básica de un archivo nacional o general, más aún cuando desde su fundación los objetivos han sido la organización y conservación de los documentos generados por la administración virreinal para su estudio y el reconocimiento de la historia, razonamiento que nos obliga a realizar un somero pero necesario análisis retrospectivo de la problemática archivística que impide tener acceso a la información en la Administración Pública Federal.

La institución que en México hace las veces de Archivo Nacional es el Archivo General de la Nación (AGN), aunque en realidad sólo tiene ascendencia sobre las dependencias y entidades de la Administración Pública. Sus obligaciones se encuentran inscritas en el Reglamento Interior de la Secretaría de Gobernación, en la sección III, con inicio en el artículo $48^{\circ}$. Sin embargo, la historia de esta institución archivística muestra cómo se generó su organización y funciones, convirtiéndose en una de las pocas que se han conservado con el paso de los siglos, desde aquel 27 de marzo de 1790 en que se creó en el Virreinato de la Nueva España.

Es importante destacar que no es intención de este artículo analizar las acciones que sobre transparencia y acceso a la información pública se tengan programadas en el AGN o en su Sistema Nacional de Archivos, pues nos son desconocidas. Lo que se pretende es manifestar el deseo mantenido durante más de 24 años de trabajo archivístico, incluyendo una estancia en el Instituto Fede-

\footnotetext{
${ }^{1}$ Reglamento Interior de la Secretaría de Gobernación, publicado en el
} Diario Oficial de la Federación, 30 de julio de 2002. ral de Acceso a la Información Pública (IFAI), de que el Archivo Nacional pueda convertirse en el líder, en la cabeza rectora de los archivos administrativos e históricos que propicie el derecho a la información y una verdadera rendición de cuentas. Esto no ha sido entendido aún entre las autoridades gubernamentales, ni las de antes ni las de ahora, incluyendo, claro está, a las de la Secretaría de Gobernación, de quien depende el AGN. En materia de derecho a la información debemos comprender que sin archivos administrativos organizados y en funcionamiento no tendremos eficiencia en la localización expedita de expedientes públicos y la Ley Federal de Transparencia y Acceso a la Información Pública Gubernamental ${ }^{2}$ no podrá cumplir sus objetivos. He ahí la razón por la cual en este texto no se hablará de otros asuntos igualmente importantes.

\section{ALGUNOS DATOS HISTÓRICOS}

\section{Del Archivo General de la Nación}

El maestro Jorge Ignacio Rubio Mañé, quien fuera un ilustre director del archivo, nos cuenta en su obra $E l$ Archivo General de la Nación, publicada en 1973, que el segundo conde de Revilla Gigedo (así se firmaba el virrey) envió al Ministerio de Gracia y Justicia de España el proyecto para crear el Archivo General de la Nueva España, con la intención de hacer más eficiente el despacho de los asuntos de gobierno. El virrey había encontrado los papeles oficiales y testimoniales de las oficinas y tribunales "sumamente confusos por la impericia o desorden en su colocación y en todos sus crecidos volúmenes de papeles antiguos" (Rubio Mañé, 1973: 15 y 16).

Uno de los objetivos fue localizar los documentos con facilidad y que éstos pudieran servir como testimonios fehacientes de los procesos administrativos, jurídicos, judiciales y de gobierno, para lo cual se planteó la necesidad de elaborar índices, imitando "como en algunas naciones

${ }^{2}$ La Ley Federal de Transparencia y Acceso a la Información Pública, Diario Oficial de la Federación, 11 de junio de 2002. 


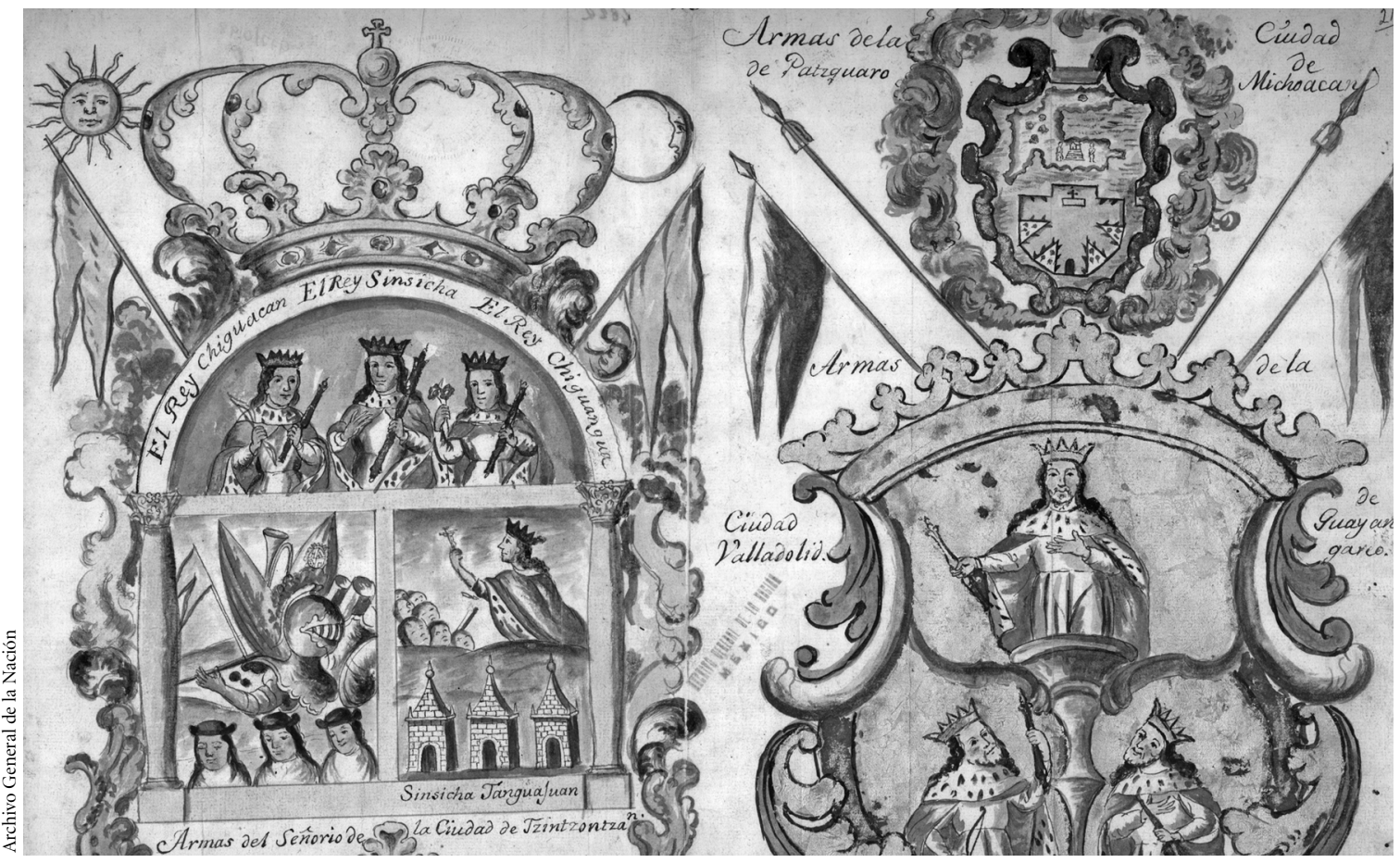

Escudo de armas de las ciudades de Pátzcuaro, Tzintzuntzan y Guayangareo (Valladolid), Michoacán, en Crónica de Michoacán, Beaumont, copia de 1972. Catálogo de ilustraciones, 211, AGN.

cultas", que la memoria documental estuviere bien organizada y consultable 3 .

El virrey Juan Vicente de Güemes Pacheco de Padilla, segundo conde de Revilla Gigedo, manifestó que "la Secretaría de Cámara del Virreinato es el eje, el tallo, la dirección de todo lo que conduce el gobierno [...] y la felicidad del Imperio de la Nueva España" (Secretaría de Gobernación, 1990: 24), razón por lo cual la columna vertebral de ese archivo general fueron los documentos y expedientes resguardados por la misma Secretaría de Cámara, aunque debemos destacar que se incluyeron papeles de don Antonio de Mendoza, primer virrey, así como de los virreyes el marqués de Casafuerte, el primer conde de Revilla Gigedo, el marqués de Amarillas, el marqués de Croix y de Antonio María de Bucareli.

\footnotetext{
${ }^{3}$ Carta del virrey Revilla Gigedo a Porlier proponiendo al rey de España la creación de un archivo general, 27 de marzo 1790, AGN Correspondencia de Virreyes, segunda serie, volumen 156, carta 444, fs. 340r-341v.
}

En realidad, el personaje que dio el primer paso para que se estableciera una organización documental, según manifestó Rubio Mañé (1973: 22), fue el secretario del virrey, el coronel Bonilla, quien arregló los primeros fondos documentales de la Secretaría de Cámara. Revilla Gigedo, conocedor de la importancia de localizar de manera expedita la información del gobierno, dejó a su sucesor, el virrey Branciforte, el documento denominado "Instrucciones de Revilla Gigedo". En ese testimonio instruye que el establecimiento del Archivo General sería de muchísima utilidad, ya que "ahora hay mucha falta de orden a la conservación de papeles" (Instrucciones..., 1973: 50, art. $139^{\circ}$ ).

En el mes de agosto de 1823, en plena construcción de la República mexicana, el Supremo Poder Ejecutivo ordenó que se organizara el Archivo General como un establecimiento de servicio público y que se depositaran en él los documentos virreinales, los del Primer Imperio y los que se generaban en esa nueva administración del 
México Independiente, bajo el denominativo de "documentos públicos”. Así nació el Archivo General y Público de la Nación.

En el reglamento del Archivo General y Público de la Nación de 1846, propuesto por José María La Fragua al Congreso General y aprobado por éste, se destacó la importancia de resguardar en el archivo todos los expedientes de asuntos concluidos de los ministerios y archivos ya existentes en las oficinas de la administración pública. El reglamento determinó que las disposiciones legislativas y los datos estadísticos, periódicos o libros se transfirieran al archivo cada año. Hasta entonces, en los acervos documentales se resguardaban documentos administrativos e históricos, y se trabajaba en su clasificación, ordenación y catalogación para su consulta. Sin embargo, para el 21 de septiembre de 1920, con el nuevo reglamento se deslindaba al archivo del control de los archivos administrativos, quedando sólo como custodio y depósito de los documentos históricos, leyes, decretos, publicaciones y obras históricas, y con la autorización de expedir copias certificadas de los mismos ${ }^{4}$.
2. Para la consulta de los documentos que amparen propiedades de su origen se hará solicitud por escrito al director fundando el derecho del peticionario y justificando su personalidad a juicio del propio director. Si éste encontrare algún inconveniente, se someterá la solicitud a superior acuerdo;

3. La copia de documentos de carácter histórico la podrán sacar las personas interesadas o un amanuense, previo permiso del director. Del comportamiento y honradez de ese amanuense se constituye fiador incondicional el interesado, quien tiene la obligación de retirarlo o substituirlo a indicación del director.

El artículo $36^{\circ}$ indica que "las Secretarías de Estado señalarán cuáles son los documentos que, habiendo pertenecido a sus archivos, deben ser tenidos como reservados. Estos documentos sólo podrán ser consultados con la autorización del titular de la Secretaría correspondiente". Y el artículo 37 manifiesta que las copias certificadas y autorizadas por el AGN harán fe en todos los tribunales, juzgados y oficinas de la República.

\section{De la problemática de los archivos de la Administración Pública Federal}

Hasta el año de 1949, aproximadamente, los archivos tuvieron dentro de la Administración Pública un alto nivel institucional y jurídico, así como una reconocida capacidad técnica y operativa en su condición de generador de servicios esenciales para los órganos de gobierno. En la Administración Pública Federal se le había dado un rango de prioridad a los servicios archivísticos, razón por lo cual "no cabe sino decir que los archivos son hoy, en comparación con lo que han sido en las etapas anteriores de su historia, lo que es la noche respecto al día" (Ampudia Mello, 1998 [1988]: 24).

Hace poco más de 57 años, aproximadamente, el país

${ }^{4}$ Desde la publicación del reglamento del Archivo General de la Nación del año de 1920 y hasta el nombramiento de la doctora Alejandra Moreno Toscano como directora general, los archivos administrativos no eran normados por el AGN. Ya con la nueva administración en el gobierno del presidente José López Portillo, el archivo se ocupó del acervo histórico nacional y de los archivos administrativos de la Administración Pública Federal. y la administración pública cambiaron y, al faltar una planeación integral para el cambio, los archivos se quedaron en un letargo y no pudieron adaptarse a las nuevas condicias y entidades. Así fueron, poco a poco, saturándose de ciones que se presentaban en cada una de las dependen- 
papeles hasta convertirse en bodegas o almacenes donde, a falta de personal capacitado, técnicas archivísticas de selección y valoración y presupuestos adecuados para su funcionamiento, se frenó el servicio archivístico y se generaron áreas de resguardo de documentos conocidas como archivos muertos.

Ese cambio, al que se le ha acreditado el retroceso de los servicios archivísticos, se consignó en el crecimiento de las estructuras orgánicas de las dependencias y entidades, así como en la rápida introducción y difusión que en ellas alcanzaron las modernas tecnologías de producción y reproducción masiva de documentos, lo que provocó otro problema para los archivos: la explosión documental, fenómeno imposible de combatir sin armas propicias para tener éxito.

Sin embargo, a partir de 1976, como parte del programa de Reforma Administrativa del Poder Ejecutivo Federal de la Secretaría de Gobernación, la Coordinación General de Estudios Administrativos de la Presidencia de la República y el propio AGN plantearon la necesidad de mejorar el funcionamiento de los archivos de las diversas instituciones gubernamentales, con el objetivo de convertirlos en órganos eficaces que coadyuvaran al cumplimiento de las atribuciones asignadas a cada una de ellas. Para tal fin se diseñó el Sistema Red de Archivos del Gobierno Federal, con el que se establecieron las bases de coordinación entre los diferentes organismos públicos (Aguilera Murguía y Nacif Mina, 2006: XIV).

Fue entonces cuando por primera ocasión se ordenó la organización de los "archivos de trámite" (a los que llamaron "unidades de documentación en trámite", de los "archivos de concentración ("unidades de documentación en concentración") y de los "archivos históricos" ("unidades de documentación histórica"). Además, se determinó la creación de una Unidad Central de Administración de Documentos, encargada de coordinar el proceso archivístico en todas las dependencias y entidades de la Administración Pública Federal, pero no se estableció la obligatoriedad de generar un servicio de consulta de la documentación administrativa activa o vigente ${ }^{5}$.

\footnotetext{
${ }^{5}$ Las dependencias y entidades de la Administración Pública Federal fir-
}

En fin, para emprender una evaluación de la problemática que el AGN enfrenta como cabeza archivística de las dependencias y entidades de la Administración Pública Federal en su tarea de garantizar el libre acceso a la información, es necesario subrayar el hecho de que todas las acciones de la Administración Pública producen o son producto de un documento por medio del cual se transmite la información generada en el manejo de los asuntos oficiales. Por esta razón, todos los documentos deben ser conservados en el repositorio denominado archivo público, donde se consultarán como testimonio fiel del cumplimiento de las atribuciones de las dependencias y entidades. Ésta es la razón por la que los documentos públicos son la columna vertebral del acceso a la información y, por ende, de la tan apelada rendición de cuentas.

Lo anterior es muestra de que los archivos son parte legítima y necesaria de la Administración Pública federal, estatal o municipal. No obstante, parecería que ni a éstas ni a sus estudiosos les ha interesado en lo más mínimo, por lo que la problemática que enfrenta el AGN para garantizar el libre acceso a la información en los archivos públicos estriba, en primera instancia, en la ineficiencia, el estancamiento, la marginalidad y el escaso servicio que estos repositorios brindan a las propias dependencias y entidades gubernamentales. En el gobierno — no sólo en el federal, sino también en los estatales y municipales- se ha considerado a los archivos como algo parecido a una bodega llena de paquetes con papeles inútiles, sin importar que contengan información fundamental para el desempeño cotidiano de las actividades y para la eficiente rendición de cuentas.

La lista de los aspectos que componen la problemática de los archivos podría ser más detallada, pero con lo comentado queda claro que existe una crisis que ha abarcado todos los niveles que se pueden considerar. Se ha constituido así un desequilibrio cabal en la organización y estructura archivística que afecta a los servicios archivísticos de las dependencias y entidades en su conjunto,

maron convenios con el AGN para instalar el Sistema Red de Archivos, lo que hicieron según sus posibilidades y ajustando el sistema a su organización. 
visión que ya había sido registrada, desde 1988, por Enrique Ampudia Mello en su obra Institucionalidad y Gobierno: un ensayo sobre la dimensión archivística de la Administración Pública.

Sin embargo, y aunque el establecimiento del Sistema Red de Archivos del Gobierno Federal tuvo como objetivo propiciar orden en la actividad archivística, por razones desconocidas no se publicó dicha normatividad en el Diario Oficial de la Federación (quedó establecida sólo en convenios firmados entre dependencias y el AGN), por lo que no se oficializó el sistema ${ }^{6}$. Como su aplicación se dio con cierta libertad, las dependencias y entidades se "autorregularon", procedimiento que, con el paso de los años dejó —en la mayoría de los casos y al no ser considerados como prioritarios- a los archivos sin un desarrollo en su organización y convertidos más en una carga que en una solución para los servicios archivísticos. Al estar ya el mal organizado, el ciclo vital de los documentos en las dependencias y entidades, columna vertebral de la administración documental y del sistema mismo, provocó la proliferación de bodegas en espera de la autorización de su baja definitiva, a pesar de la lucha sin cuartel que para evitarlo estableció el AGN en aquellos años ${ }^{7}$.

\section{EL PROBLEMA EN LA ACTUALIDAD}

\section{El marco normativo}

Debemos entender que las obligaciones actuales del AGN no se limitan al servicio de consulta de documentos históricos resguardados en los acervos y galerías, como se podría pensar por ser el custodio oficial de la memoria histórico-documental; sus obligaciones abarcan mucho más. Naturalmente, la conservación de los testimonios, la descripción de los expedientes y documentos, la difu-

\footnotetext{
${ }^{6}$ Varias dependencias - como la Secretaría de Salud y el extinto Departamento del Distrito Federal, entre otros- publicaron en el Diario Oficial los acuerdos con los que se establecía el Sistema Red de Archivos. ${ }^{7}$ Para corroborar la existencia de bodegas basta con visitar los archivos de concentración, llamados "archivos muertos". Existen honrosas excepciones, como el archivo de concentración de la Secretaría de Salud, Pemex Petroquímica, en Coatzacoalcos, Veracruz, y otros más.
}

sión de los fondos documentales resguardados son parte de las acciones archivísticas, pero se requiere también el trabajo en los archivos administrativos de las dependencias y entidades, los cuales, al ser originales y sustantivos, formarán parte de esa memoria histórica que no puede ser reservada, sino que es pública por su propia naturaleza.

Nuestro Archivo General debe ser el líder, el hilo conductor en el derecho a la información, tanto de manera interna como para los archivos administrativos e históricos del Gobierno Federal. Lo afirmamos no porque creemos que esa obligación la haya adquirido a partir de la publicación de la Ley Federal de Transparencia y Acceso a la Información Pública Gubernamental, sino porque propiciar y generar los medios para cumplir con el derecho a la información pública consagrado por el artículo $6^{\circ}$ de la Constitución Política de los Estados Unidos Mexicanos es parte de la esencia misma de un archivo nacional. Por desgracia parecería que ese derecho se convirtió en una tragedia archivística para las dependencias y entidades de la Administración Pública Federal a partir del momento en que la Ley Federal de Transparencia y Acceso a la Información Pública Gubernamental obligó a la organización de los archivos ${ }^{8}$, reaccionando como si fuera una imposición y no una obligación, olvidando que mucho antes de que existiera una Ley de Transparencia ya se contaba con un marco jurídico en la materia que, al parecer, no se ha respetado en su totalidad. Con la intención de dar ejemplos de este marco normativo y de manera informativa se reproduce parte de sus contenidos:

\section{1) Ley General de Bienes Nacionales (08 enero 1982) ARTículo $2^{\circ}$. Son bienes de dominio público:}

XI. Los muebles de propiedad federal que por su naturaleza no sean normalmente substituibles, como los documentos y expedientes de las oficinas; los manuscritos, incunables, ediciones, libros, documentos, publicaciones periódicas, mapas, planos, folletos y grabados importan-

\footnotetext{
${ }^{8}$ El artículo Décimo Transitorio de la Ley Federal de Transparencia y Acceso a la Información Pública Gubernamental establece que: "Los sujetos obligados deberán, a más tardar el $1^{\circ}$ de enero de 2005 , completar la organización y funcionamiento de sus archivos administrativos, así como la publicación de la guía a la que se refiere el artículo $32^{\circ}$."
} 


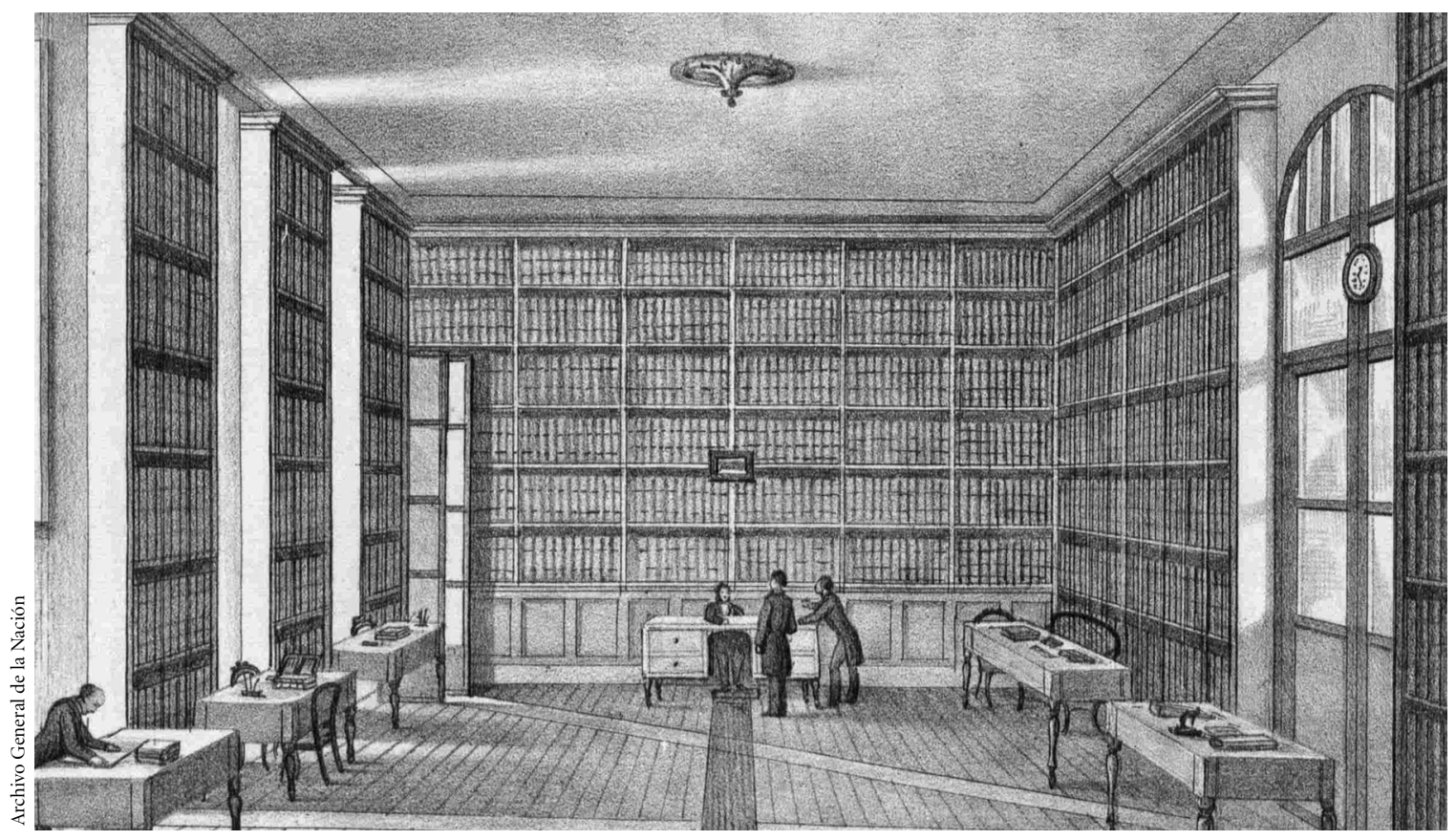

Archivo general y público de la Nación, lit. de Murguía. México pintoresco-Palacio Nacional.

tes o raros, así como las colecciones de esos bienes; las piezas etnológicas y paleontológicas; los especímenes tipo de la flora y de la fauna; las colecciones científicas o técnicas, de armas, numismáticas y filatélicas; los archivos, las fono grabaciones, películas, archivos fotográficos, cintas magnetofónicas y cualquier otro objeto que contenga imágenes y sonidos, y las piezas artísticas o históricas de los museos.

2) Ley Federal sobre Monumentos y Zonas Arqueológicos, Artísticos e Históricos (06 mayo 1972)

ARTíCULO $36^{\circ}$. Por determinación de esta Ley son monumentos históricos:

II. Los documentos y expedientes que pertenezcan o hayan pertenecido a las oficinas y archivos de la Federación, de los Estados o de los Municipios y de las casas curiales.

III. Los documentos originales manuscritos relacionados con la historia de México y los libros, folletos y otros impresos en México o en el extranjero, durante los siglos XVI al XIX, que por su rareza e importancia para la historia mexicana merezcan ser conservados en el país.
3) Código Penal Federal (14 agosto 1931)

ARTíCUlO $214^{\circ}$. Comete el delito de ejercicio indebido de servicio público, el servidor público que:

IV. Por sí o por interpósita persona, sustraiga, destruya, oculte, utilice, o inutilice ilícitamente información o documentación que se encuentre bajo su custodia o a la cual tenga acceso, o de la que tenga conocimiento en virtud de su empleo, cargo o comisión.

ARTíCUlO $381^{\circ}$. Además de la pena que le corresponda conforme a los artículos $370^{\circ}$ y $371^{\circ}$, se aplicarán al delincuente las penas previstas en este artículo, en los casos siguientes:

XIV. Cuando se trate de expedientes o documentos de protocolo, oficina o archivos públicos, de documentos que contengan obligación, liberación o transmisión de deberes que obren en expediente judicial, con afectación de alguna función pública. Si el delito lo comete el servidor público de la oficina en que se encuentre el expediente o documento, se le impondrá además destitución e inhabilitación para desempeñar otro empleo, cargo o comisión públicos, de seis meses a tres años. 


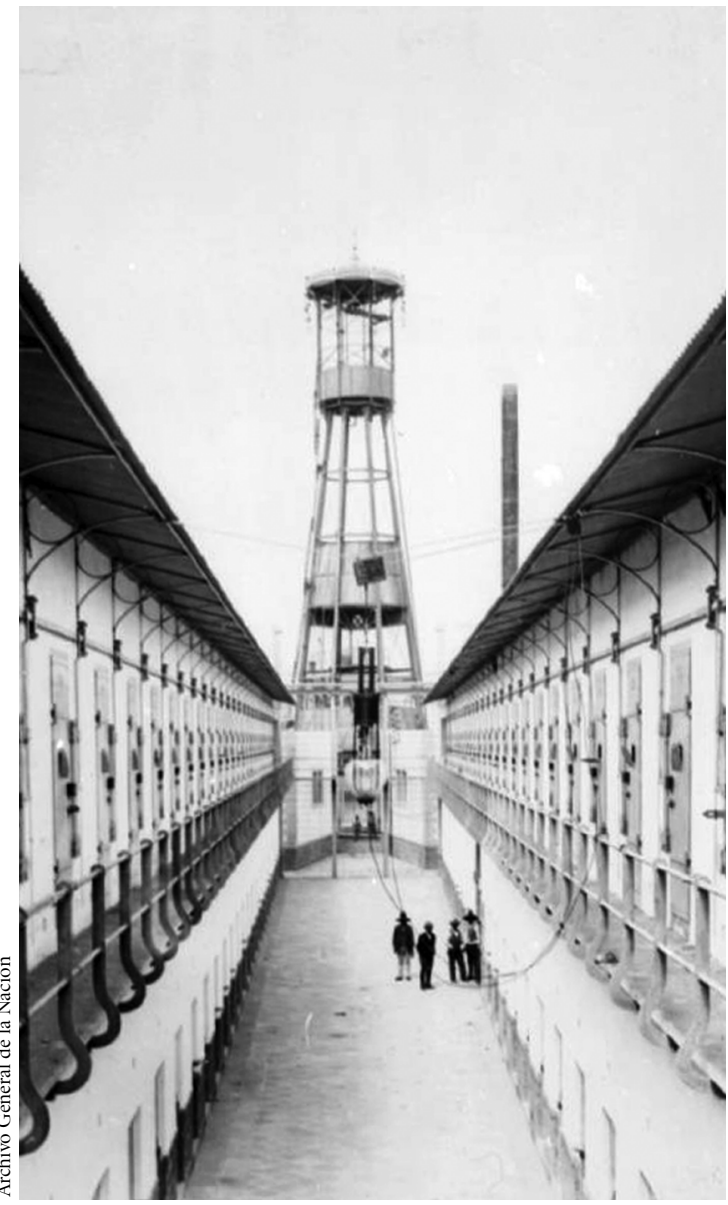

El palacio de Lecumberri cuando era penitenciaría. Álbum de la construcción de la Penitenciaría de la ciudad de México. Centro de Información Gráfica “Torre Panóptica”, AGN.

4) Código Federal de Procedimientos Penales (30 agosto 1934)

ARTíCULO $280^{\circ}$. Los documentos públicos harán prueba plena, salvo el derecho de las partes para redargüirlos de falsedad y para pedir su cotejo con los protocolos o con los originales existentes en los archivos.

\section{5) Reglamento del Archivo General de la Nación (13 abril} 1946)

ARTíCUlO $6^{\circ}$. Ningún documento de los comprendidos en la fracción I del artículo $1^{\circ}$ y el artículo $3^{\circ}$ podrá ser destruido o enajenado sin el permiso correspondiente de la persona designada por la Dirección del Archivo para que dictamine sobre su valor histórico y la conveniencia de su destrucción o enajenación.

6) Acuerdo por el que se establecen los Lineamientos a que se sujetará la guarda, custodia y plazo de conservación del Archivo Contable Gubernamental (25 agosto 1998)

ARTículo $3^{\circ}$. El tiempo de guarda de los documentos que integran el Archivo Contable Gubernamental será de cinco años, contado a partir del ejercicio siguiente a aquel en que se elabore el documento.

Tratándose de la documentación que ampare inversiones en activos fijos y en obras públicas, así como aquella que sirva de base para el fincamiento de responsabilidades o procesos judiciales, deberá conservarse como mínimo durante un periodo de doce años.

En caso de que otras disposiciones jurídicas establezcan plazos mayores a los señalados para la conservación de dicha documentación, se estará a lo establecido por éstas.

\section{Los documentos de los delitos cometidos contra personas vinculadas con movimientos sociales y políticos del pasado}

Existen dos publicaciones importantes para el derecho a la información pública en México y al manejo que al respecto debe establecer el AGN. Una de ellas apareció en el Diario Oficial de la Federación el 27 de noviembre de 2001, mucho antes de que se publicara la Ley Federal de Transparencia y Acceso a la Información Pública Gubernamental, y causó gran expectativa, no sólo entre los historiadores y archivistas, sino entre la sociedad. Se trata del "Acuerdo por el que se disponen diversas medidas para la procuración de justicia por delitos cometidos contra personas vinculadas con movimientos sociales y políticos del pasado", que en el capítulo III establece la apertura de los archivos institucionales.

${ }^{9}$ Este acuerdo fue publicado en el Diario Oficial de la Federación el 27 de noviembre de 2001. 
Es posible que lo que aquí se diga no sea en realidad nada nuevo para los lectores, pero a causa de ese documento, el AGN experimentó cambios y conflictos de importancia en el servicio de consulta que, al ser de documentos históricos, no están sujetos a ninguna reserva, ni antes ni en la actualidad; es decir, son públicos.

En el capítulo de referencia, en el artículo $5^{\circ}$ se establece que: "Para el debido cumplimiento de este Acuerdo, la Secretaría de Gobernación transferirá al Archivo General de la Nación la totalidad de los archivos, expedientes documentos e información en general generados por las extintas Dirección Federal de Seguridad y Dirección General de Investigaciones Políticas y Sociales, que en la actualidad se encuentran bajo custodia y conservación del Centro de Investigación y Seguridad Nacional, a efecto de que puedan ser consultados en los términos del presente Acuerdo" 10 .

En el artículo $6^{\circ}$ se estableció que la Secretaría de Gobernación realizaría gestiones para que todas las Secretarías de Estado, así como el gobierno del Distrito Federal, transfirieran al AGN la información que pudiera servir para la investigación de hechos del pasado relacionados con violaciones a los derechos humanos o constitutivos probablemente de delitos contra personas vinculadas con movimientos sociales y políticos. Se requirió también al Departamento del Distrito Federal la documentación del llamado "Servicio Secreto"11.

El artículo $7^{\circ}$ faculta al AGN para convertirse en la institución fundamental en la aplicación del derecho a la información al establecer que:

El Archivo General de la Nación deberá recibir, custodiar, organizar y conservar los archivos, documentos y expedientes que conformen los acervos que le son transferidos por virtud del presente Acuerdo.

\footnotetext{
${ }^{10}$ Es conveniente aclarar que en 1998, siendo la directora general del AGN la maestra Patricia Galeana Huerta, en cumplimento del artículo $35^{\circ}$, fracción III del Reglamento Interior de la Secretaría de Gobernación, se dieron a consulta pública los expedientes, documentos e información en general generados por las extintas Dirección Federal de Seguridad y Dirección General de Investigaciones Políticas y Sociales del año de 1968, resguardados en el AGN, y cada año se liberaron para la consulta aquellos que cumplían su temporalidad.

${ }^{11}$ Hasta donde se tiene noticia, el gobierno del Distrito Federal no respondió al llamado del artículo $6^{\circ}$, fracción II del acuerdo de referencia.
}

La información transferida y que hubiere sido generada hasta el año de 1985 inclusive podrá ser consultada por cualquier interesado sin más restricciones que las que establece el marco jurídico, en los términos de la legislación aplicable y conforme a los procedimientos determinados en la normatividad vigente en el Archivo General de la Nación para garantizar la integridad y la adecuada conservación de la misma.

Y el artículo $8^{\circ}$ enmarca la temporalidad para que esa documentación pueda ser consultada sin restricciones:

La información de las dependencias cuya generación sea posterior a 1985, sea o no transferida al Archivo General de la Nación, estará a disposición de las instancias competentes del Poder Judicial de la Federación, de la Procuraduría General de la República, de la Comisión Nacional de los Derechos Humanos y de las demás competentes en la materia que, en ejercicio de sus respectivas atribuciones, deban consultarla, una vez satisfechos los requisitos que procedan y en los términos de la legislación aplicable.

Dentro del ambiente archivístico y del derecho a la información, los artículos $7^{\circ}$ y $8^{\circ}$ ayudan a determinar que la documentación generada hasta 1985 inclusive está sujeta a la consulta pública y, en caso de existir datos personales, las autoridades del Archivo deberán elaborar versiones públicas de dicha documentación para ser consultada. Aquella documentación posterior a ese año podría reservarse a las instancias que se mencionan en el propio artículo.

El otro documento, publicado en el Diario Oficial de la Federación el martes 18 de junio de 2002 y firmado por Santiago Creel Miranda, secretario de Gobernación, integra los "Lineamientos para la apertura de los archivos, expedientes e información que fueron transferidos al Archivo General de la Nación en cumplimiento del acuerdo por el que se disponen diversas medidas para la procuración de justicia por delitos cometidos contra personas vinculadas con movimientos sociales y políticos del pasado".

El documento es producto de la aprobación, por parte del Consejo Técnico del Archivo General de la Nación en sesión extraordinaria celebrada el 3 de junio de 2002 ${ }^{12}$,

\footnotetext{
${ }^{12}$ En esta fecha, la directora general del AGN era la doctora Stella María
} 
de los lineamientos para la apertura de los archivos, expedientes y documentos que fueron transferidos al propio Archivo y que serán puestos a disposición de los interesados $^{13}$, en cumplimiento tanto del acuerdo presidencial del 27 de noviembre de 2001 como de la Ley Federal de Transparencia y Acceso a la Información Pública Gubernamental, en todo y específicamente en el tratamiento de los datos personales contenidos en los archivos y expedientes ${ }^{14}$

Del capítulo II en adelante, los lineamientos informan sobre los pasos a seguir para exponer a la consulta pública los archivos y expedientes que comento ${ }^{15}$, ya que todos los demás fondos documentales, expedientes y documentos, al ser históricos, no están sujetos a tal normatividad, sino que son públicos. Y eso es lo extraño, ya que al ser transferidos al Archivo Histórico Central del AGN es porque sus valores administrativos, legales y contables han culminado y, por ende, no deberían tener restricción alguna ${ }^{16}$.

Los documentos que hemos analizado nos muestran que no existe impedimento oficial para que los expediende los delitos cometidos contra personas vinculadas con movimientos sociales y políticos del pasado estén sujetos a la consulta pública. Todos los interesados pueden tener acceso a ellos como lo establece el artículo $4^{\circ}$ :

Las solicitudes de acceso se atenderán en el siguiente orden de prelación:

a) Las autoridades competentes en materia de procuración y administración de justicia.

b) Las personas cuyos datos personales se encuentren en los archivos o expedientes, por sí mismas o por medio de su representante legal, o de sus familiares, en línea recta ascendente y descendente hasta el segundo grado, y en línea transversal hasta el primer grado.

González Cicero, promotora incansable de los archivos y del derecho a la información.

${ }^{13}$ Artículo $1^{\circ}$ de los Lineamientos de referencia.

${ }_{14}$ Artículo $2^{\circ}$ de los Lineamientos de referencia.

${ }^{15}$ Nos pareció innecesario reproducir los Lineamientos, ya que se encuentran en el Diario Oficial de la Federación, 18 de junio de 2002.

${ }^{16}$ La restricción para la consulta de documentos históricos se puede dar en caso de que sea parte de un proceso judicial como prueba y, por ende, esté custodiado por el Ministerio Público. c) Los investigadores como parte de sus trabajos académicos.

Las solicitudes de acceso de cualquier otro interesado se tramitarán en el mismo orden en que hubieren sido presentadas.

Frente a los datos anteriores, y al menos que haya existido algún acuerdo no público entre autoridades que provoque lo contrario, la documentación puede ser consultada sin problema alguno, y cada una de las áreas del AGN — la Dirección General, el Archivo Histórico Central y el Centro de Referencias Documentales- tiene la obligación de velar que así sea ${ }^{17}$.

\section{CONCLUSIONES}

\section{El derecho a la información pública y los archivos}

Con lo antes expuesto podemos observar que una de las causas para que el derecho a la información pública no se cumpla es que "la administración pública ha descuidado la verdadera administración de documentos. Si analizamos el proceso de documentos que se genera en la gestión administrativa y el flujo de papeles que va de un lado a otro por las oficinas, se confirmaría que existe una reproducción irracional de documentos que, a la postre, crean duplicidad de funciones, saturación en el almacenamiento, ineficiencia y gastos inútiles" (Aguilera Murguía y Nacif Mina, 2006: XV), y evitan la localización expedita de los expedientes ${ }^{18}$, proceso básico para la consulta pública en cualquier archivo. Tal situación se ha dado por la falta de una planeación en la generación de documentos que permita identificar el "documento de archivo" (aquel que registra un hecho, acto administrativo, jurídico, fiscal o contable, creado, recibido, manejado y usado en el ejercicio de las facultades

\footnotetext{
17 Queda una duda en el tintero: ¿por qué personal del Centro de Investigación y Seguridad Nacional (Cisen) es el encargado de determinar acerca de la custodia y servicio de consulta de esos documentos dentro del AGN?

${ }^{18}$ Consideramos que la localización expedita de expedientes y documentos es un paso primordial en el derecho a la información pública gubernamental, pues propicia que los archivos dejen de ser depósitos de cajas contenedoras de documentos sin organizar.
} 


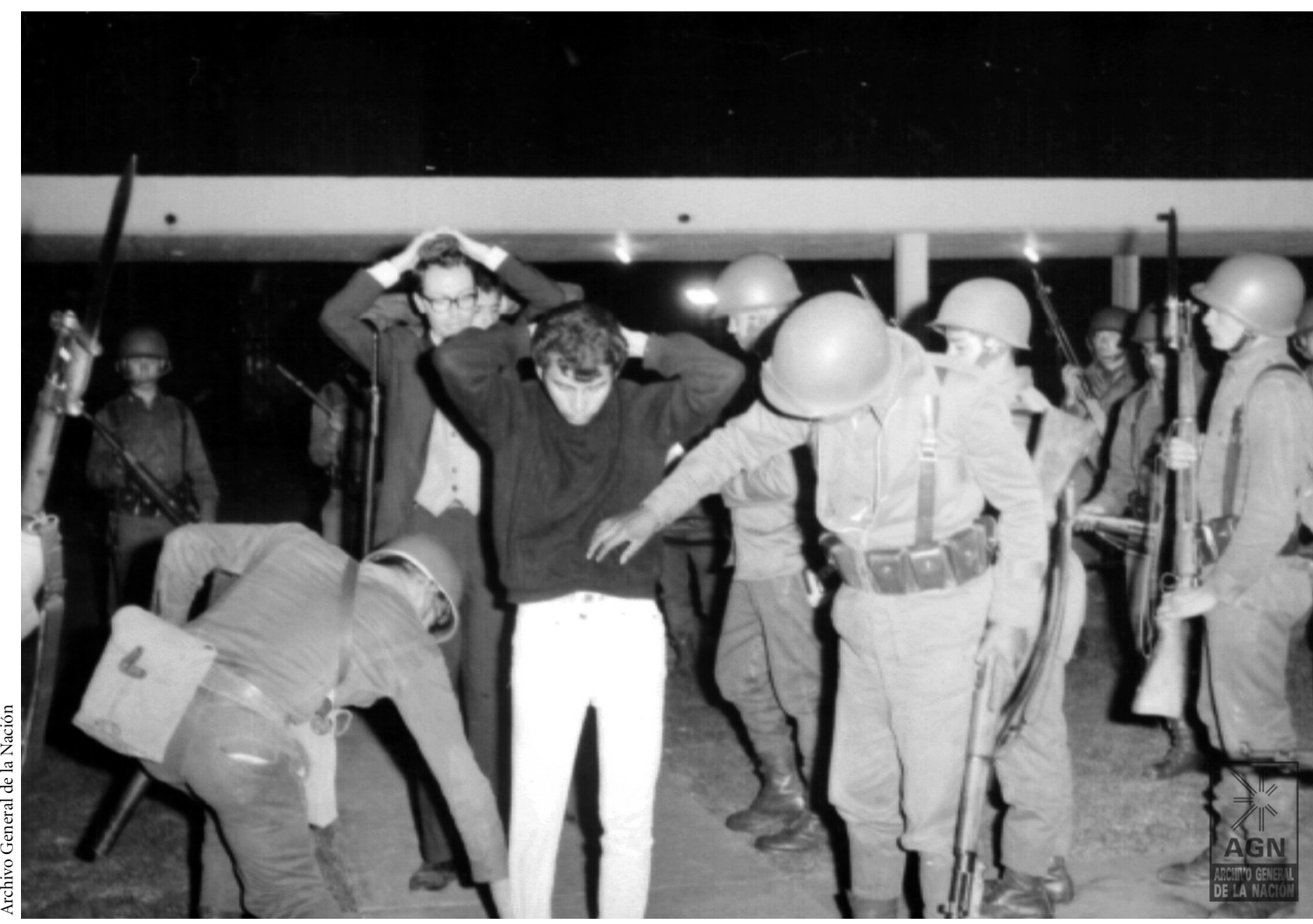

Movimiento estudiantil de 1968. Hermanos Mayo concentrados, AGN.

y actividades de las dependencias y entidades $)^{19}$ de un documento que no lo es.

De manera categórica e indiscutible, el problema rector que el AGN debe resolver para garantizar el libre acceso a la información - tanto interna en sus archivos administrativos como en los archivos administrativos de las dependencias y entidades- es el de la falta de una valoración documental ${ }^{20}$. Aunque ésta ha sido considerada como un dilema, en realidad es un proceso lógico

\footnotetext{
${ }^{19}$ Numeral segundo, fracción XV de los "Lineamientos Generales para la organización y conservación de los archivos de las dependencias y entidades de la Administración Pública Federal", publicado el 20 de febrero de 2004 en el Diario Oficial por el AGN y el IFAI.

${ }^{20}$ La valoración documental no se debe quedar en la ejecución de ciertas acciones que sirven para dictaminar el destino final de la documentación mediante la revisión de inventarios y listados, cuando el proceso real debe ser el análisis de expediente por expediente.
}

que tiene como objetivo conservar los expedientes (unidades documentales constituidas por uno o varios documentos de archivo, ordenados y relacionados por un mismo asunto, actividad o trámite de una dependencia o entidad) que, al pertenecer a una serie documental, son reflejo fiel de la dependencia o entidad pública que los generó, y que con ellos se puede ejercer el derecho a la información y la rendición de cuentas ${ }^{21}$.

Por lo tanto, se debe considerar la valoración documental no sólo como un proceso para separar lo que se va y lo que se queda en un archivo de trámite o de concentración, sino como una actitud que nace del servidor público ante el documento y que le da la posibilidad de vis-

\footnotetext{
${ }^{21}$ En varios cursos y pláticas dadas por personal del IFAI —incluyéndonos - se ha manifestado que los archivos son la columna vertebral del acceso a la información.
} 
lumbrar el efecto informativo que un documento tiene en el presente y que podrá tener en el futuro próximo, tanto para la propia administración pública como para el cumplimiento, primero, del artículo $6^{\circ}$ constitucional y, después, de la Ley Federal de Transparencia y Acceso a la Información Pública Gubernamental.

Es importante destacar que para los legisladores que elaboraron esta ley fue clara la idea de que sin una adecuada organización, clasificación y manejo de los documentos, difícilmente puede haber acceso a la información. No se debe, por tanto, hacer nugatorio el ejercicio de este derecho ya sea por la negligencia de los servidores públicos o por la falta de un marco regulatorio claro que no deje lugar a dudas de cómo deben manejarse los archivos. Razón necesaria para la redacción del artículo $32^{\circ}$ de la misma, que establece que: "Corresponderá al Archivo General de la Nación elaborar, en coordinación con el Instituto, los criterios para la catalogación, clasificación y conservación de los documentos administrativos, así como la organización de archivos de las dependencias y entidades".

La falta de normatividad en la materia ha tenido, como hemos comentado, a la información soportada en documentos públicos inmersa en paquetes, atados y cajas guardados en galerones con techumbre de cartón, en estacionamientos ocupando cajones destinados originalmente a vehículos con separación de tabla roca, sótanos insalubres y hasta cuartos de azoteas de los inmuebles gubernamentales, en espera de ser dados de baja o destruidos, ya fuera porque los plazos de conservación se vencieron sin que se revisaran sus contenidos o por las malas condiciones que provocan la humedad, el calor excesivo y los microorganismos que se generan a causa del polvo y la basura que comparten el espacio con expedientes y documentos.

Cierto es, primero se debió legislar sobre una ley de archivos que diera certidumbre al acceso a la información pública gubernamental y permitiera asegurar la organización en cada uno de los archivos de la Administración Pública Federal. En este punto y después de mucho trabajar, el AGN remitió a la Secretaria de Gobernación en 2002 un borrador de ley de archivos para que se revisara y enviará como iniciativa al Congreso de la Unión, que- dando por lo menos como un antecedente. Sin embargo, nada se supo al respecto y la Ley Federal de Transparencia y Acceso a la Información Pública entró en vigor en el año de $2003^{22}$.

Es necesario reconocer que el equipo directivo de aquellos años del AGN influyó en la redacción inicial del artículo $32^{\circ}$ y Décimo Transitorio de la comentada ley, con la intención de que, dentro del instrumento legislativo, no quedaran fuera los archivos. Era necesario que por lo menos un artículo de la ley obligara a la administración pública a atender sus archivos administrativos, los cuales habían estado ya muy descuidados.

El resultado del artículo $32^{\circ}$ de la Ley Federal de Transparencia y Acceso a la Información Pública Gubernamental son los lineamientos generales para la organización y conservación de los archivos de las dependencias y entidades de la Administración Pública Federal, publicado en el Diario Oficial de la Federación el 20 de febrero de 2004, después de largas reuniones de trabajo entre el AGN y el Instituto Federal de Acceso a la Información Pública. Se hizo así oficial la primera normatividad para la organización y conservación de archivos en las dependencias y entidades de la Administración Pública Federal, con la firme intención de dar los primeros pasos para la regulación de esa actividad fundamental y prioritaria, poniendo sobre la mesa los problemas archivísticos que se deben resolver para garantizar el acceso a la información. Ya el segundo párrafo del artículo $32^{\circ}$ de la ley manifiesta que los titulares de las dependencias y entidades, de conformidad con las disposiciones aplicables, deberán asegurar el adecuado funcionamiento de los archivos y elaborar y poner a disposición del público una guía simple de sus sistemas de clasificación y catalogación, así como de la organización del archivo. Éste es el primer contacto de los archivos públicos con la transparencia y el acceso a la información pública, y representa el reto inicial de los responsables de su funcionamiento en las dependencias y entidades.

22 En marzo de 2000, en el Foro de Consulta sobre la Ley Nacional de Archivos propiciado por la LVII Legislatura, se discutió una propuesta presentada por la fracción parlamentario del PRD, propuesta que fue rechazada por insuficiente. 
Los lineamientos de referencia establecen los criterios de organización y conservación de la documentación contenida en los archivos con el objeto de que se conserven íntegros y disponibles para permitir y facilitar el acceso a la información. De ahí que en las dependencias y entidades la organización de sus archivos deberá asegurar la disponibilidad, localización expedita, integridad y conservación de los documentos de archivo que poseen, ya fueran administrativos de trámite o administrativos de concentración, teniéndolos dispuestos para su consulta y así, de alguna manera, garantizar el acceso a la información, lo que se logrará con un sistema archivístico apegado a los lineamientos que se comentan.

Para que el sistema archivístico funcione y garantice el acceso a la información pública es necesario que las dependencias y entidades, así como sus delegaciones o equivalentes, determinen el número de áreas de control de gestión necesarias para recibir y distribuir la documentación de entrada; registrar y controlar la documentación de entrada y de salida, y recibir y despachar la documentación de salida de sus áreas administrativas. Es ahí, en el control de gestión documental, donde inicia la construcción archivística, ya que es el vínculo que remite la documentación a los archivos de trámite para ser integrados a expedientes ya existentes o abrir nuevos, respetando la clasificación archivística oficial.

Los lineamientos en comento son una guía oficial para la organización del sistema archivístico, ya que establecen la conformación de los tres tipos de archivos: trámite, concentración e histórico, y sus funciones básicas, mismas que permiten, con su aplicación, adoptar medidas para administrar y conservar los documentos, integrados en expedientes, generados o recibidos, cuyo contenido y estructura permitan identificarlos como documentos de archivo, asegurando la identidad e integridad de su información y propiciando su acceso a la consulta pública.

Sin embargo, para organizar o establecer lo que se ha llamado la reingeniería archivística, se requiere que en las dependencias y entidades se cuente con un área administrativa que, dedicada de tiempo completo a los archivos, se convierta en la cabeza de ese sistema archivístico. Mientras se encarga de estructurar la organización archivística, deberá apoyar a los comités de información (creados por el artículo $29^{\circ}$ de la Ley Federal de Transparencia y Acceso a la Información Pública Gubernamental) en la elaboración de criterios específicos en la materia, así como en la elaboración de los procedimientos archivísticos que faciliten el acceso a la información. Por eso en el numeral sexto de los lineamientos se recomienda la creación de un área coordinadora de archivos, que debe de funcionar como la columna vertebral del sistema archivístico de las dependencias y entidades de la Administración Pública. Para que las dependencias y entidades propicien la organización, conservación y localización expedita de los archivos administrativos se requiere que los titulares se aseguren de la elaboración de los instrumentos de consulta y control archivístico básicos, siendo éstos: 1) el cuadro general de clasificación archivística (instrumento técnico que refleja la estructura de un archivo con base en las atribuciones y funciones de cada dependencia o entidad); 2) el catálogo de disposición documental (registro general y sistemático que establece los valores documentales, los plazos de conservación, la vigencia documental, la clasificación de reserva o confidencialidad y el destino final de la documentación); 3) los inventarios documentales (instrumentos de consulta que describen las series y expedientes de un archivo y que permiten su localización por medio del inventario general; su transferencia, con el inventario de transferencia, o su baja documental, con el inventario de baja documental), y 4) el nuevo instrumento que incorpora el artículo $32^{\circ}$ de la ley, la guía simple de archivos (esquema general de descripción de las series documentales de los archivos de una dependencia o entidad, que indica sus características fundamentales conforme al cuadro general de clasificación y sus datos generales) ${ }^{23}$.

Los titulares de los archivos públicos, y el propio AGN, deben comprender que con la Ley Federal de Transparencia y Acceso a la Información Pública Gubernamental el

\footnotetext{
${ }^{23}$ Es importante destacar que cuando la ley establece la elaboración de la guía simple de archivos no se refiere a la guía general del archivo, sino a un instrumento de transparencia para los archivos que, como lo marca el numeral séptimo de los Lineamientos Generales, deberá contener la descripción básica de sus series documentales, es decir, el resumen de sus contenidos.
} 
trabajo en los archivos se ha modificado, ha cambiado positivamente, ya que ahora se dirige con la perspectiva de tener expedientes ordenados para cumplir con el derecho a la información, y sus instrumentos de consulta y control se convierten en documentos públicos, apoyo fundamental para la consulta de los archivos, ya fueran de trámite o de concentración.

Ahora los archivistas deben vencer y olvidar aquella regla no escrita que gobernó por más de treinta años en la Administración Pública Federal y que establecía que los archivos sólo podían ser consultados por aquellas áreas administrativas que los habían generado y nadie más — iclaro, a menos que existiera una orden judicial!Como todo aquello que se archivaba ya no servía, pues nadie lo consultaba, y lo que servía se encontraba guardado en la oficina generadora y no en un archivo público. Hoy en día la consigna es trabajar para ordenar el futuro desde los archivos ${ }^{24}$

Finalmente, es importante destacar que la Ley Federal de Transparencia y Acceso a la Información Pública Gubernamental no sanciona a los archivos históricos, y que fieren a los archivos administrativos. Así, los fondos documentales históricos resguardados en el Archivo Histórico Central del AGN son públicos y, en caso de contener datos personales, será necesario elaborar versiones públicas para su consulta.

También es importante precisar que la normatividad acerca de los archivos de los delitos cometidos contra personas vinculadas con movimientos sociales y políticos del pasado que hemos analizado nos muestra que no existe impedimento oficial para que los expedientes generados hasta 1985 estén sujetos a la consulta pública. Todos los interesados pueden tener acceso a ellos tal como lo establece el artículo $4^{\circ}$ de los lineamientos para su consulta.

Consideramos que el liderazgo del AGN ante la era de la transparencia y el acceso a la información pública gubernamental en la organización de los archivos administrativos e históricos de México está sujeto a la tarea que en

${ }^{24}$ La doctora María Marván Laborde manifestó en varias ocasiones que organizar los archivos era ordenar el futuro.

materia de asesoría y capacitación apegada a la normatividad vigente ${ }^{25}$ se proyecte frente a los archivos de la administración pública. Deberá evitar convertirse en un auditor o verificador del cumplimiento de dicha norma y sí en un asesor cuyo objetivo sea propiciar el derecho a la información y la rendición de cuentas, acciones que a cuatro años de la publicación de los Lineamientos Generales en la materia no se han cumplido en todas las dependencias y entidades de la Administración Pública Federal.

\section{Siglas y bibliografía}

\section{AGN: Archivo General de la Nación}

Ampudia Melo, José Enrique, 1998 [1988], Institucionalidad y Gobierno. Un ensayo sobre la dimensión archivística de la Administración Pública, Instituto Nacional de Administración Pública, Archivo General de la Nación, México.

Aguilera Murguía, Ramón y Jorge Nacif Mina, 2006, Los archivos públicos: su organización y conservación, Miguel Ángel Porrúa, México.

Instrucciones que los Virreyes de Nueva España dejaron a sus sucesores, 1973, t. II, Biblioteca Histórica de la Iberia, México.

Rubio Mañé, Jorge Ignacio, 1973, El Archivo General de la Nación, Archivo General de la Nación, México

Secretaría de Gobernación, 1990, "Breve historia del Archivo General de la Nación", en Guía general del Archivo General de la Nación, Secretaría de Gobernación.

${ }^{25}$ La normatividad vigente fue publicada en el Diario Oficial de la Federación por la Secretaría de Gobernación y firmada en primera instancia por el director general del AGN y por el pleno del IFAI, el 20 de febrero de 2004. 